\title{
Involvement of the WNT and FGF signaling pathways in non-isolated anorectal malformations: Sequencing analysis of WNT3A, WNT5A, WNT11, DACT1, FGF10, FGFR2 and the $T$ gene
}

\author{
MARKUS DRAAKEN $^{1,2^{*}}$, WIEBKE PRINS $^{3^{*}}$, CLAUDIA ZEIDLER $^{3 *}$, ALINA HILGER $^{1}$, SADAF S. MUGHAL $^{1}$, \\ JEANETTE LATUS $^{3}$, THOMAS M. BOEMERS ${ }^{4}$, DOMINIK SCHMIDT ${ }^{1,5}$, EBERHARD SCHMIEDEKE ${ }^{1,6}$, \\ NICOLE SPYCHALSKI ${ }^{7}$, ENRIKA BARTELS ${ }^{1}$, MARKUS M. NÖTHEN ${ }^{1,2}$, \\ HEIKO REUTTER $^{1,8}$ and MICHAEL LUDWIG ${ }^{3}$
}

\begin{abstract}
${ }^{1}$ Institute of Human Genetics, ${ }^{2}$ Department of Genomics, Life and Brain Center and ${ }^{3}$ Department of Clinical Chemistry and Clinical Pharmacology, University Hospital of Bonn, D-53127 Bonn; ${ }^{4}$ Department of Pediatric Surgery and Pediatric Urology, Children's Hospital, D-50735 Köln; ${ }^{5}$ Department of Pediatric Surgery, Campus Virchow Clinic, Charité University Hospital Berlin, D-13353 Berlin; ${ }^{6}$ Department of Pediatric Surgery and Urology,

Center for Child and Adolescent Health, Hospital Bremen-Mitte, D-28205 Bremen; ${ }^{7}$ Department of Pediatric Surgery, Cnopf'sche Kinderklinik, D-90419 Nürnberg; ${ }^{8}$ Department of Neonatology, Children's Hospital, University Hospital of Bonn, D-53127 Bonn, Germany
\end{abstract}

Received July 23, 2012; Accepted August 7, 2012

DOI: $10.3892 / \mathrm{ijmm} .2012 .1124$

\begin{abstract}
Anorectal malformations (ARMs) comprise a broad spectrum of anomalies, including anal atresia, congenital anal fistula and persistence of the cloaca. Research suggests that genetic factors play an important role in ARM development. However, few genetic variants have been identified. Embryogenesis is orchestrated by crosstalk of the wingless-type MMTV integration site family (WNT) and fibroblast growth factor (FGF) signaling pathways in a process that involves several intracellular cascades. Studies in mice have implicated several genes from these pathways in the etiology of ARMs. We performed sequencing analysis of seven of these previously reported genes in 78 patients with ARMs occurring within the context of at least one additional congenital anomaly. No associations were identified with variants in WNT3A, WNT5A, WNT11, DACT1, FGF10 or the T gene. In the $F G F R 2$ gene, three novel heterozygous nucleotide substitutions were identified. Further investigations, including the study of family members, revealed that these variants were not causally related to the phenotype in the present
\end{abstract}

Correspondence to: Professor Michael Ludwig, Department of Clinical Chemistry and Clinical Pharmacology, University Hospital of Bonn, 25 Sigmund Freud street, D-53127 Bonn, Germany

E-mail: mludwig@uni-bonn.de

*Contributed equally

Key words: anorectal malformation, brachyury, candidate genes, dapper homolog 1 , fibroblast growth factor, fibroblast growth factor receptor, wingless-type MMTV integration site family
ARM cohort. Mutations in the seven investigated genes may nonetheless be a cause of ARMs in rare cases. However, further studies should consider genes encoding other proteins in the WNT/FGF signaling pathways as possible candidates.

\section{Introduction}

Anorectal malformations (ARMs) comprise a broad spectrum of anomalies including anal atresia, congenital anal fistula and persistence of the cloaca. The estimated incidence of ARMs is approximately 1 in 2,500 to 3,000 live births (1-5) and a male to female ratio of 1.7 has been reported for isolated (non-syndromic) forms (6). Isolated forms account for 40-50\% of all ARM cases, and these are sometimes associated with other developmental anomalies, such as renal and urogenital malformations $(5,6)$. In the remaining cases, ARMs occur within the context of defined genetic syndromes or multiple congenital anomalies.

Research suggests that ARMs have a heterogeneous etiology and include Mendelian and multifactorial forms. The latter probably arise as a result of a complex interplay between genetic risk variants and environmental factors. Possible maternal risk factors include use of multivitamins or medications for severe chronic dyspepsia and asthma during pregnancy $(7,8)$, periconceptional injuries or pyrexia, obesity and diabetes. Research also suggests that smoking and certain occupational exposures in either parent may be associated with a higher risk of ARMs (9-12).

Although mutations for some ARM-related syndromes have been identified, the majority of the underlying genetic factors for ARMs remain unknown $(13,14)$. Previously reported genetic factors include the homeobox gene MNX1 in Currarino syndrome (15), the SALL1 zinc-finger protein in 


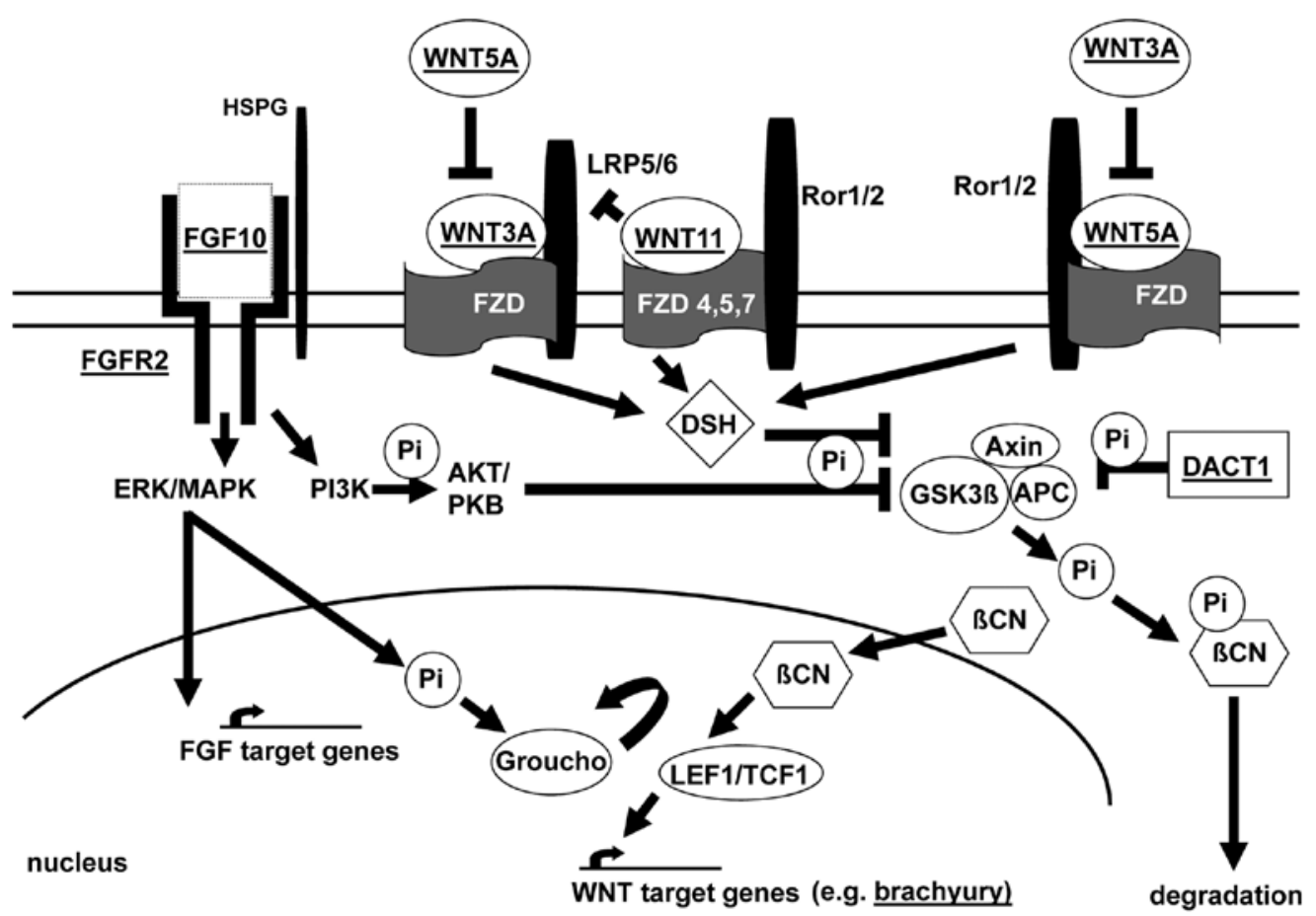

Figure 1. Molecular FGF/WNT signaling factor pathways as candidates for ARM. Selected proteins and interactions are shown. FGF signal transduction (binding of FGF10 to its receptor FGFR2) is shown. Formation of the FGF:FGFR:HSPG (heparan sulfate proteoglycans) signaling complex activates extracellular signal-regulated kinases (ERK)/mitogen-activated protein kinases (MAPK) and phosphoinositide-3 kinase (PI3K). PI3K activates protein kinase AKT or protein kinase B (PKB), with subsequent inhibition of glycogen synthase kinase $3 \beta$ (GSK3 $\beta$ ) by phosphorylation. MAPK dependent phosphorylation of transcription factors allows transcription of FGF target genes. In addition, phosphorylation may promote the release of transcriptional repressor Groucho from transcription factor (TCF) 1 . This allows interaction between TCF/lymphoid enhancer-binding factor 1 (LEF1) and $\beta$-catenin ( $\beta C N$ ) and stimulation of the transcription of WNT-dependent genes, e.g. the $T$-gene (brachyury). In the absence of nuclear $\beta C N$, TCF1/LEF1 act as transcriptional repressors by binding to Groucho. $\beta C N$ can also displace Groucho from TCF1/LEF1. Stabilization of $\beta C N$ is the major effect of WNT signaling. Absence of this effect leads to phosphorylation of $\beta \mathrm{CN}$ via a destruction complex including axin, the APC gene (mutant in adenomatous polyposis) product and GSK $3 \beta$. This mechanism primes $\beta C N-P i$ for degradation by the ubiquitin pathway. WNT ligands include the Frizzled (FZD) family of receptors and these signal through co-receptors such as low-density lipoprotein receptor related protein 5/6 (LRP5/6) and the orphan tyrosine kinase receptors ROR1 and ROR2. Binding of WNT3A (inhibited by WNT5A) to a receptor from the Frizzled (FZD) family leads to the activation of Dishellved (DSH), a core component of WNT signaling, thereby enhancing the phosphorylation and subsequent inhibition of GSK3 $\beta$. In addition to FZD receptors, WNT5A can also bind and activate ROR2, resulting in the activation of the actin-binding protein filamin A and the JNK signaling pathway. WNT3A and WNT5A exert reciprocal pathway inhibition. WNT11 binds to several FZD (type 4, 5 and 7) receptors. Inhibition of WNT/ $\beta C N$ signaling may be mediated by competition for FZD receptors. DACT1 can bind $\beta C N$ and this complex then inhibits GSK3 $\beta$. This inhibition represses the destruction complex and leads to the release of $\beta \mathrm{CN}$, thereby increasing its nuclear and cytoplasmic fraction. The figure is adapted from previous studies (31,60-62).

Townes-Brocks syndrome (16) and the GLI3 gene in PallisterHall syndrome (17).

Since many ARM phenotypes are negatively associated with reproductive fitness, it is reasonable to assume that a substantial proportion of ARM patients carry de novo mutations. Thus candidate gene sequencing to identify rare, high-penetrance mutations is a rational approach.

The processes of urogenital and anorectal embryogenesis involves the wingless-type MMTV integration site family (WNT)/fibroblast growth factor (FGF) signaling pathways. Mammalian WNT proteins constitute a family of roughly 20 secreted glycoproteins (18), which act as short-range paracrine signaling effectors. The FGF family comprises 22 extracellular ligands, whose signals are mediated through a family of tyrosine kinase receptors. These are termed the five FGF receptors (FGFR1-5) (19). Alternative splicing generates multiple isoforms for each FGFR. Each isoform is characterized by a differing affinity for the respective ligand (20).

Multiple lines of evidence from mouse models suggest that genes in these signaling pathways (Fig. 1) are implicated in the etiology of ARMs. Mice that are homozygous for a hypomorphic Wnt3a allele display vertebral defects, a short tail due to loss of caudal vertebrae, deficient cloacal development and incomplete uro-rectal septation (21). Moreover, studies involving human pluripotent stem cells have shown that WNT3A is required for hindgut specification (22). $W n t 5 a$ is expressed in the embryonic colon and rectum and affects the development of the proximal cloacal plate (23). Wnt $5 a$-knockout mice display ARMs such as imperforate anus and the presence of fistulas between the urinary and intestinal tracts (24). As with Wnt3a and Wnt5a, Wnt11 has been identified in the developing mouse urogenital tract (25). Two studies have reported expression of human WNT11 in the embryonic uro-rectal septum, the urogenital folds, the labioscrotal swellings and the epithelium of the esophagus and colon $(26,27)$. Studies in Chinese hamster ovary cells have shown that Wnt11 signaling leads to downregulation of the key signaling pathways Wnt/ $\beta$-catenin, JNK/AP- 1 and NF-кB (28).

Dapper homolog 1 (Dact1) also functions as a negative regulator of Wnt signaling (29), and its inactivation leads to perinatal lethality in Dact ${ }^{--}$mice. Wen et al (30) 


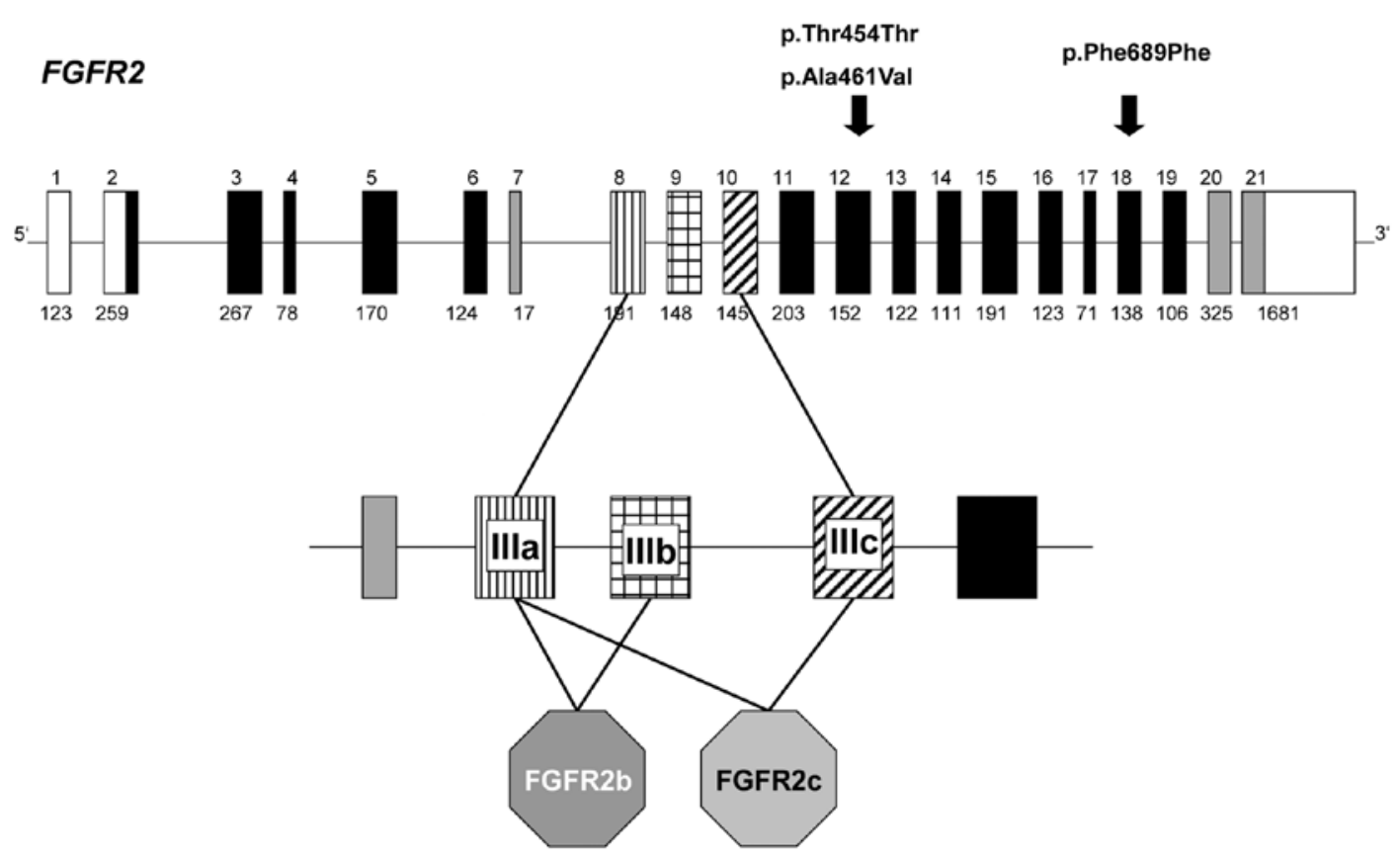

Figure 2. Organization of the human FGFR2 gene. Common coding regions are marked in black and exons used only in several isoforms are marked in grey. The $5^{\prime}$ and $3^{\prime}$ untranslated regions are indicated by white boxes. Alternative splicing of the third Ig-like domain (shaded) through the use of two exclusive exons (IIIb and IIIc) is shown at the bottom of the figure. Size of the exons is given in base pairs. Variants detected in the present cohort of 78 ARM patients are indicated by arrowheads at the top of the figure.

reported that the phenotype of Dact null embryos resembled human congenital caudal regression syndrome, including features such as caudal vertebrae agenesis, ARMs, renal agenesis/dysplasia, fused kidneys and absence of the bladder.

The orchestration of embryogenesis via crosstalk of the WNT and FGF signaling pathways is mediated by several intracellular cascades (19,31), and integration of WNT/FGF signaling can also occur at the level of an individual gene promoter (32). The $T$ gene (brachyury; T-box containing transcription factor) is a direct target of WNT3A signaling during paraxial mesoderm specification (33), and a $T$ missense mutation (p.Ala338Val) has been observed in four patients with sacral agenesis/anorectal atresia $(34,35)$. Bagai et al (36) reported that FGF10 plays an important role in regulating the growth, differentiation and repair of the urothelium. Other studies found that complete invalidation of fibroblast growth factor $10(F G F 10)$ in mice resulted in a genetically reproducible ARM (37) and failure of ventral fusion in the urethral plate (38).

FGF10 signaling is mediated by the FGFR2 protein, which is encoded by the receptor encoding gene FGFR2. Mutations in this gene cause various forms of autosomal dominant craniosynostosis syndrome and have been associated with ARMs in patients with Apert syndrome (acrocephalosyndactyly type I; MIM, 101200), Pfeiffer syndrome types 1 and 2 (acrocephalosyndactyly type V; MIM, 101600), Crouzon syndrome (craniofacial dysostosis; MIM, 123500) and Beare-Stevenson cutis gyrata syndrome (MIM, 123790) (39-47).

To explore the possible involvement of the above genes in the etiology of human ARMs, we performed sequencing analysis in a sample of 78 patients with ARMs occurring within the context of multiple congenital anomalies.

\section{Patients and methods}

Subjects. Patients were contacted and recruited through the German self-help organization for patients with anorectal malformations (SoMA e.V.) as well as the Departments of (i) Neonatology, Children's Hospital, University of Bonn, (ii) Paediatric Surgery and Urology, Centre for Child and Adolescent Health, Hospital Bremen-Mitte, (iii) Pediatric Surgery and Pediatric Urology, Children's Hospital, Cologne, (iv) Pediatric Surgery, Campus Virchow Clinic, Charité University Hospital Berlin and (v) Pediatric Surgery, Cnopf'sche Kinderklinik, Nuremberg. Blood samples were taken from the patients and (if available) their parents ( $n=55$ trios). In 18 cases only one parent agreed to participate and in five cases no parental sample could be obtained.

All 78 ARM patients were of European descent and had a normal karyotype. The study was approved by the Ethics Committee of the University of Bonn and written informed consent was obtained from all subjects prior to inclusion and blood sampling.

Gene analysis. Standard procedures were used for the isolation of genomic DNA, amplification of DNA via polymerase chain reaction (PCR) and performance of the automated sequencing analyses. In brief, primers (sequences available on request) were directed to all exons of the genes WNT3A, WNT5A, WNT11, DACT1, FGF10, FGFR2 and $T$ (GenBank acc. nos.: NM_033131.3, NM_001256105.1, NM_004626.2,NM_016651.5, NM_004465.1, NM_000141.4, NM_001144913.1-001144919.1, NM_022970.3 and NM_003181.2). The resultant PCR products were subjected to direct automated sequencing (3130xl Genetic Analyzer; Applied Biosystems, Foster City, CA, USA). For each patient, 
both strands of each amplicon were sequenced. All nucleotide variations were confirmed via the performance of independent PCR reactions. Segregation of these variants in family members was investigated by sequencing the respective PCR products. In the course of direct sequencing, information was obtained concerning various single nucleotide polymorphisms (SNPs) in the analyzed genes.

RNA analysis. RNA analyses were performed to determine the effect of the DNA variation observed in index patient (case B10) and his mother. The respective blood samples were collected in PAXgene tubes (PreAnalytiX, Hombrechtikon, Switzerland) in order to stabilize the intracellular RNA. RNA for reverse transcription (RT) PCR was prepared with the RNeasy Plus Micro kit (Qiagen, Hilden, Germany) in accordance with the manufacturer's instructions. Primers were directed to $F G F R 2$ exons 10/11 (10/11F-cDNA: 5'-GACAGTTCTGCCAGCGCCTG-3') and 13 (13R-cDNA: 5'-GCCTCCTTGGGCTTGTCTTTG-3'). This allowed analysis of the effect of the c.G2012A (p.Thr454=) variant (numbering according to GenBank acc. no. NM_022970.3 and Swiss-Prot entry P21802) and detection of alternatively spliced mRNAs.

\section{Results}

In our candidate gene approach no variant of likely causal relevance was detected in the genes encoding WNT3A, WNT5A, WNT11, DACT1, FGF10 and T protein. Sequencing analysis of the FGFR2 gene revealed the presence of novel heterozygous variants in three patients (Fig. 2). These variants are listed neither in the current SNP database (dbSNP136) nor in the 1,000 Genomes catalog.

A synonymous p.Thr454= variant $($ c.G2012A transition in exon 12) was identified in patient B10 and his mother. Patient B10 presented with anal atresia with fistula, hypospadias, left renal agenesis, rib and vertebral column malformations, lumbar spina bifida occulta and hexadactylism of the right foot. Interestingly, his mother also had spina bifida occulta. A closer look at the sequence surroundings affected by this silent substitution, revealed the formation of a potential novel 3 ' acceptor splice site in exon 12. Calculation of the consensus value (CV) for splice site recognition (48) revealed a CV of 0.913 for the wild-type sequence $\left(5^{\prime}\right.$-cattttgtatccag ${ }^{\wedge} \mathrm{G}$; exonic base in capital letter) and a CV of 0.917 for the novel variant (5'-cctctcttcaacag ${ }^{\wedge} \mathrm{C}$; substitution underlined). The finding of nearly identical CVs suggested an alternative usage of these splice sites with the possible consequence of a deletion of $76 \mathrm{bp}$ (p.Ala455GlnfsX26). Therefore, RNA analysis was performed. However, no novel 425-bp fragment (normal, $501 \mathrm{bp}$ ) was detected in the RT-PCR experiments (data not shown). The only detected variation was due to alternative splicing at the exon 11 donor splice site, which has been shown to account for the absence of residues Val428 and Thr429 in several FGFR2 isoforms (see Swiss-Prot entry P21802).

Another heterozygous exon 12 FGFR2 variant (c.C2032T) was detected in patient G10. This variant is predicted to result in a p.Ala461Val amino acid substitution. Patient G10 presented with perineal fistula, hypoplasia of the left thumb, pre-axial polydactyly of the left hand, wedged vertebra (thoracic and cervical), rib malformations, dextroversio cordis and double kidney (left). The mother showed wild-type sequence only, and no DNA was available from the father. To test if this variant had arisen de novo on the maternal allele, a search for neutral heterozygous variants $5 \mathrm{~kb}$ upstream and downstream of exon 12 was performed. Detection of such variants would have allowed allele-specific PCR, and a distinction as to whether the variant resided on the maternal or the paternal allele. However, no heterozygous SNP or private variant was detected in the 10-kb flanking exon 12 . Interestingly, pathogenicity prediction of this sequence alteration varied depending on the program used. According to Mutation Taster (www.mutationtaster.org), this variant had a 0.981 probability of being disease-causing. In contrast, three other programs predicted that it was benign: [PolyPhen-2 (http://genetics.bwh.harvard.edu/pph2/, benign with a score of 0.005); MutPred (http://mutpred.mutdb.org, probability of being deleterious 0.235); and SNPs\&Go (http://snps-and-go. biocomp.unibo.it/cgi-bin/snps-and-go/runpred.cgi, reliability index 1].

A third variant was identified in patient $\mathrm{A} 02$, who presented with anal atresia with recto-urethral prostatic fistula, ventricular septal defect, subaortic stenosis and dystopic kidney. This synonymous FGFR2 exon 18 variant (c.C2717T, p.Phe689=) was assumed to have no effect. Hence, no further analyses of this variant were performed.

Direct sequencing also generated information concerning several SNPs (dbSNP136) in the investigated genes. For all genes, similar haplotype data were found in the European Population of the International HapMap Project, the CEPH (Centre d'Etude du Polymorphisme Human) pedigrees and the PDR90 (The NIH Polymorphism Discovery Resource; 90 individual screenings) subset.

\section{Discussion}

WNT/FGF signaling pathways (Fig. 1) orchestrate correct patterning, cell specification and tissue differentiation during embryogenesis $(19,31)$. Research has shown that disruption of this coordinated interplay can result in severe malformations in mice and humans $(49,50)$, including urogenital and anorectal anomalies. The present study investigated selected candidate genes from these pathways, chosen on the basis of observations in mice and human cell lines and/or their involvement in diseases associated with ARMs. However, no potential causal variant for ARMs was detected in the genes encoding WNT3A, WNT5A, WNT11, DACT1, FGF10 and T protein in the present cohort.

In contrast, $F G F R 2$ analysis revealed the presence of novel heterozygous variations in three patients (Fig. 2). We initially considered the two exon 12 variants to be of potential causal relevance. Our rationale for this hypothesis was that as well as affecting all FGFR2 isoforms, a mutation in this exon would affect a cytoplasmic part of the protein which has not yet been implicated in the various forms of autosomal dominant craniosynostosis syndrome. Moreover, the program Mutation Taster (51) predicted that the p.Ala461Val amino acid substitution was disease-causing. However, Thusberg et al (52) reported on the suboptimal performance of this program and in line with their findings 
of the performance of mutation pathogenicity prediction methods, several other - more reliable - programs classified it as benign. Furthermore, the results of our mRNA experiments suggest that the p.Thr454= variant had no effect on correct splicing.

Despite these negative findings, the possibility remains that these nucleotide substitutions contribute to the ARM phenotype through as-yet-unknown mechanisms. As FGF10 is expressed in the mesenchyme that lies adjacent to the urethral plate, a plausible hypothesis is that it is important in the regulation of endoderm and/or mesenchyme growth, and thus in proliferation-driven urogenital and anorectal development $(37,38)$. Interestingly, ARM patient B10 and his mother - both of whom showed spina bifida occulta - carried the silent p.Thr454= variant. Severe spinal dysraphism has been observed in association with an FGFR2 p.Ser351Cys mutation (53) and spina bifida occulta occurs in the mouse mutant Brachyury curtailed $\left(T^{/+}\right)$(54). However, whereas $T^{\mathrm{c}+}$ mice are tailless, several of the FGFR2 amino acid substitutions observed in patients with Beare-Stevenson (55), Crouzon and Pfeiffer syndromes (56) are associated with sacral appendage. These findings, together with the repeated observation of ARMs in mice $(37,38)$ and patients with FGFR2 defects (39-47), imply that this FGF signaling pathway is of crucial importance in normal caudal development, rendering the coincidental co-occurrence of these defects unlikely.

In summary, no significant association between ARMs and mutations in WNT3A, WNT5A, WNT11, DACT1, FGF10, $F G F R 2$ or the $T$ gene was found in the present cohort. However, although our patient cohort was larger than those used in previous candidate gene studies of ARMs (34,57-59), the sample size may have been too small to detect rare causal mutational events. Furthermore, we cannot exclude the possibility that mutations in the promoter region, in as yet unknown regulatory sequences or in non-coding regions that are not detectable with the method applied were overlooked. Future studies should consider additional proteins of the WNT/FGF signaling pathways as possible candidates.

\section{Acknowledgements}

M.D., A.H., S.S.M., E.S., E.B., M.M.N., H.R. and M.L. are members of the 'Network for the Systematic Investigation of the Molecular Causes, Clinical Implications and Psychosocial Outcome of Congenital Uro-Rectal Malformations (CURE-Net)', which is supported by a research grant (01GM08107) from the German Federal Ministry of Education and Research (Bundesministerium für Bildung und Forschung, BMBF). S.S.M. is supported by a research grant from the Richard-Winter-Stiftung. G.D. and E.B. are supported by the BONFOR program of the University of Bonn, grant nos. O-149.0096 and O-149.0099, respectively. We thank all patients and family members for their cooperation, as well as the German Self-Help Organization for People with Anorectal Malformations (SoMA e.V.). We thank Pia Uerdingen for her excellent technical assistance and Dr Christine Schmael for her expert advice regarding the manuscript.

\section{References}

1. Smith ED: Incidence, frequency of types and aetiology of anorectal malformations. Birth Defects Orig Artic Ser 24: 231-246, 1988

2. Cho S, Moore SP and Fangman T: One hundred three consecutive patients with anorectal malformations and their associated anomalies. Arch Pediatr Adolesc Med 155: 587-591, 2001.

3. Cuschieri A; EUROCAT Working Group: Descriptive epidemiology of isolated anal anomalies: a survey of 4.6 million births in Europe. Am J Med Genet 103: 207-215, 2001.

4. Levitt MA and Peña A: Anorectal malformations. Orphanet J Rare Dis 2: 33, 2007.

5. Stoll C, Alembik Y, Dott B and Roth MP: Associated malformations in patients with anorectal anomalies. Eur J Med Genet 50: 281-290, 2007.

6. Cuschieri A; EUROCAT Working Group: Anorectal anomalies associated with or as part of other anomalies. Am J Med Genet 110: 122-130, 2002.

7. Acs N, Bánhidy F, Puhó EH and Czeizel AE: A possible association between maternal dyspepsia and congenital rectal/ anal atresia/stenosis in their children: a population-based casecontrol study. Acta Obstet Gynecol Scand 88: 1017-1023, 2009.

8. Lin S, Munsie JPW, Herdt-Losavio ML, Druschel CM, Campbell K, Browne ML, Romitti PA, Olney RS and Bell EM; National Birth Defects Prevention Study: Maternal asthma medication use and the risk of selected birth defects. Pediatrics 129: e317-e324, 2012.

9. Van Rooij IA, Wijers CH, Rieu PN, Hendriks HS, Brouwers MM, Knoers NV, de Blaauw I and Roeleveld N: Maternal and paternal risk factors for anorectal malformations: a Dutch case-control study. Birth Defects Res A Clin Mol Teratol 88: 152-158, 2010.

10. Hackshaw A, Rodeck C and Boniface S: Maternal smoking in pregnancy and birth defects: a systematic review based on 173 687 malformed cases and 11.7 million controls. Hum Reprod Update 17: 589-604, 2011

11. Tinker SC, Reefhuis J, Dellinger AM and Jamieson DJ: Maternal injuries during the periconceptional period and the risk of birth defects, National Birth Defects Prevention Study, 1997-2005. Paediatr Perinat Epidemiol 25: 487-496, 2011.

12. Zwink N, Jenetzky E and Brenner H: Parental risk factors and anorectal malformations: systematic review and meta-analysis. Orphanet J Rare Dis 6: 25, 2011.

13. Solomon B: VACTERL/VATER Association. Orphanet J Rare Dis 6: $56,2011$.

14. Mundt E and Bates MD: Genetics of Hirschsprung disease and anorectal malformations. Semin Pediatr Surg 19: 107-117, 2010.

15. Belloni E, Martucciello G, Verderio D, Ponti E, Seri M, Jasonni V, Torre M, Ferrari M, Tsui LC and Scherer SW: Involvement of the HLXB9 homeobox gene in Currarino syndrome. Am J Hum Genet 66: 312-319, 2000.

16. Kohlhase J, Wischermann A, Reichenbach H, Froster U and Engel W: Mutations in the SALL1 putative transcription factor gene cause Townes-Brocks syndrome. Nat Genet 18: 81-83, 1998.

17. Kang S, Graham JM Jr, Olney AH and Biesecker LG: GLI3 frameshift mutations cause autosomal dominant Pallister-Hall syndrome. Nat Genet 15: 266-268, 1997.

18. Clevers H: Wnt/beta-catenin signaling in development and disease. Cell 127: 469-480, 2006.

19. Dorey K and Amaya E: FGF signalling: diverse roles during early vertebrate embryogenesis. Development 137: 3731-3742, 2010.

20. Zhang X, Ibrahimi OA, Olsen SK, Umemori H, Mohammadi M and Ornitz DM: Receptor specificity of the fibroblast growth factor family. The complete mammalian FGF family. J Biol Chem 281: 15694-15700, 2006.

21. Van de Ven C, Bialecka M, Neijts R, Young T, Rowland JE, Stringer EJ, van Rooijen C, Meijlink F, Nóvoa A, Freund JN, et al: Concerted involvement of Cdx/Hox genes and Wnt signaling in morphogenesis of the caudal neural tube and cloacal derivatives from the posterior growth zone. Development 138: 3451-3462, 2011.

22. Spence JR, Mayhew CN, Rankin SA, Kuhar MW, Vallance JE, Tolle K, Hoskins EE, Kalinichenko VV, Wells SI, Zorn AM, Shroyer NF and Wells JM: Directed differentiation of human pluripotent stem cells into intestinal tissue in vitro. Nature 470: 105-109, 2011. 
23. Nakata M, Takada Y, Hishiki T, Saito T, Terui K, Sato Y, Koseki H and Yoshida $\mathrm{H}$ : Induction of Wnt5a-expressing mesencymal cells adjacent to the cloacal plate is an essential process for its proximodistal elongation and subsequent anorectal development. Pediatr Res 66: 149-154, 2009.

24. Tai CC, Sala FG, Ford HR, Wang KS, Li C, Minoo P, Grikscheit TC and Bellusci S: Wnt5a knock-out mouse as a new model of anorectal malformation. J Surg Res 156: 278-282, 2009.

25. Mehta V, Abler LL, Keil KP, Schmitz CT, Joshi PS and Vezina CM: Atlas of Wnt and $R$-spondin gene expression in the developing male mouse lower urogenital tract. Dev Dyn 240 2548-2560, 2011.

26. Lako M, Strachan T, Bullen P, Wilson DI, Robson SC and Lindsay S: Isolation, characterisation and embryonic expression of WNT11, a gene which maps to 11q13.5 and has possible roles in the development of skeleton, kidney and lung. Gene 219: 101-110, 1998

27. Lickert H, Kispert A, Kutsch S and Kemler R: Expression patterns of Wnt genes in mouse gut development. Mech Dev 105: 181-184, 2001

28. Railo A, Nagy II, Kilpeläinen $P$ and Vainio S: Wnt-11 signaling leads to down-regulation of the Wnt/ $\beta$-catenin, JNK/AP-1 and NF- B pathways and promotes viability in the CHO-K1 cells. Exp Cell Res 314: 2389-2399, 2008

29. Cheyette BN, Waxman JS, Miller JR, Takemaru K, Sheldahl LC, Khlebtsova N, Fox EP, Earnest T and Moon RT: Dapper, a Dishevelled-associated antagonist of beta-catenin and JNK signaling, is required for notochord formation. Dev Cell 2: 449-461, 2002

30. Wen J, Chiang YJ, Gao C, Xue H, Xu J, Ning Y, Hodes RJ, Gao X and Chen YG: Loss of Dact1 disrupts planar cell polarity signaling by altering dishevelled activity and leads to posterior malformation in mice. J Biol Chem 285: 11023-11030, 2010.

31. Pownall ME and Isaacs HV: FGF signalling in vertebrate development. In: Developmental Biology, Book 2, Kessler DS (ed); Morgan \& Claypool Life Sciences, CA, pp14-16 2010.

32. Haremaki T, Tanaka Y, Hongo I, Yuge $M$ and Okamoto $H$ : Integration of multiple signal transducing pathways on $\mathrm{Fg}$ response elements of the Xenopus caudal homologue Xcad3. Development 130: 4907-4917, 2003

33. Yamaguchi TP, Takada S, Yoshikawa Y, Wu N and McMahon AP: $\mathrm{T}$ (brachyury) is a direct target of Wnt3a during paraxial mesoderm specification. Genes Dev 13: 3185-3190, 1999.

34. Papapetrou C, Drummond F, Reardon W, Winter R, Spitz L and Edwards $\mathrm{YH}$ : A genetic study of the human $\mathrm{T}$ gene and its exclusion as a major candidate gene for sacral agenesis with anorectal atresia. J Med Genet 36: 208-213, 1999.

35. Ghebranious N, Blank RD, Raggio CL, Staubli J, McPherson E, Ivacic L, Rasmussen K, Jacobsen FS, Faciszewski T, Burmester JK et al: A missense T (Brachyury) mutation contributes to vertebral malformations. J Bone Miner Res 23: 1576-1583, 2008.

36. Bagai S, Rubio E, Cheng JF, Sweet R, Thomas R, Fuchs E, Grady R, Mitchell M and Bassuk JA: Fibroblast growth factor-10 is a mitogen for urothelial cells. J Biol Chem 277: 23828-23837, 2002.

37. Fairbanks TJ, De Langhe S, Sala FG, Warburton D, Anderson KD, Bellusci S and Burns RC: Fibroblast growth factor 10 (Fgf10) invalidation results in anorectal malformation in mice. J Pediatr Surg 39: 360-365, 2004.

38. Yucel S, Liu W, Cordero D, Donjacour A, Cunha G and Baskin LS: Anatomical studies of the fibroblast growth factor-10 mutant, Sonic Hedge Hog mutant and androgen receptor mutant mouse genital tubercle. Adv Exp Med Biol 545: 123-148, 2004.

39. Ohashi H, Nishimoto H, Nishimura J, Sato M, Imaizumi S, Aihara T and Fukushima Y: Anorectal anomaly in Pfeiffer syndrome. Clin Dysmorphol 2: 28-33, 1993.

40. Park WJ, Meyers GA, Li X, Theda C, Day D, Orlow SJ, Jones MC and Jabs EW: Novel FGFR2 mutations in Crouzon and Jackson-Weiss syndromes show allelic heterogeneity and phenotypic variability. Hum Mol Genet 4: 1229-1233, 1995.

41. Park WJ, Theda C, Maestri NE, Meyers GA, Fryburg JS, Dufresne C, Cohen MM Jr and Jabs EW: Analysis of phenotypic features and FGFR2 mutations in Apert syndrome. Am J Hum Genet 57: 321-328, 1995.
42. Pfeiffer RA, Rinnert S, Popp R and Röckelein G: Asymmetrical coronal synostosis, cutaneous syndactyly of the fingers and toes, and jejunal atresia in a male infant. Am J Med Genet 63: 175-176, 1996.

43. Przylepa KA, Paznekas W, Zhang M, Golabi M, Bias W, Bamshad MJ, Carey JC, Hall BD, Stevenson R, Orlow SJ, et al: Fibroblast growth factor receptor 2 mutations in BeareStevenson cutis gyrata syndrome. Nat Genet 13: 492-494, 1996.

44. LeHeup BP, Masutti JP, Droullé P and Tisserand J: The AntleyBixler syndrome: report of two familial cases with severe renal and anal anomalies. Eur J Pediatr 154: 130-133, 1995.

45. Schaefer F, Anderson C, Can B and Say B: Novel mutation in the FGFR2 gene at the same codon as the Crouzon syndrome mutations in a severe Pfeiffer syndrome type 2 case. Am J Med Genet 75: 252-255, 1998.

46. Křepelová A, Baxová A, Calda P, Plavka R and Kapras J: FGFR2 gene mutation (Tyr375Cys) in a new case of Beare-Stevenson syndrome. Am J Med Genet 76: 362-364, 1998.

47. Kodaka T, Kanamori Y, Sugiyama M and Hashizume K: A case of acrocephalosyndactyly with low imperforate anus. J Pediatr Surg 39: E32-E34, 2004.

48. Shapiro MB and Senapathy P: RNA splice junctions of different classes of eukaryotes: sequence statistics and functional implications in gene expression. Nucleic Acids Res 15: 7155-7174, 1987.

49. Wilkie AO: Bad bones, absent smell, selfish testes: The pleiotropic consequences of human FGF receptor mutations. Cytokine Growth Factor Rev 16: 187-203, 2005.

50. Shifley ET and Cole SE: The vertebrate segmentation clock and its role in skeletal birth defects. Birth Defects Res C Embryo Today 81: 121-133, 2007.

51. Schwarz JM, Rödelsperger C, Schuelke M and Seelow D: MutationTaster evaluates disease-causing potential of sequence alterations. Nat Methods 7: 575-576, 2010.

52. Thusberg J, Olatubosun A, Vihinen M: Performance of mutation pathogenicity prediction methods on missense variants. Hum Mutat 32: 358-368, 2011.

53. Chun K, Siegel-Bartelt J, Chitayat D, Phillips J and Ray PN: FGFR2 mutation associated with clinical manifestations consistent with Antley-Bixler syndrome. Am J Med Genet 77: 219-224, 1998

54. Park CHT, Pruitt JH and Bennett D: A mouse model for neural tube defects: The curtailed $\left(\mathrm{T}^{\mathrm{c}}\right)$ mutation produces spina bifida occulta in $\mathrm{T} /+$ animals and spina bifida with meningomyelocele in $\mathrm{T}^{\mathrm{T}} / \mathrm{t}$. Teratology 39: 303-312, 1989.

55. McGaughran J, Sinnott S, Susman R, Buckley MF, Elakis G, Cox T and Roscioli T: A case of Beare-Stevenson syndrome with a broad spectrum of features and a review of the FGFR2 Y375C mutation phenotype. Clin Dysmorphol 15: 89-93, 2006.

56. Shanske AL, Staffenberg D and Goodrich JT: Sacral appendage in a child with an FGFR2 mutation: a report and review. Am J Med Genet A 146A: 2172-2175, 2008.

57. Seri M, Martucciello G, Paleari L, Bolino A, Priolo M, Salemi G, Forabosco P, Caroli F, Cusano R, Tocco T, et al: Exclusion of the Sonic Hedgehog gene as responsible for Currarino syndrome and anorectal malformations with sacral hypodevelopment. Hum Genet 104: 108-110, 1999.

58. Krüger V, Khoshvaghti M, Reutter H, Vogt H, Boemers TM and Ludwig M: Investigation of FGFIO as a candidate gene in patients with anorectal malformations and exstrophy of the cloaca. Pediatr Surg Int 24: 893-897, 2008.

59. Agochukwu NB,Pineda-Alvarez DE, Keaton AA, Warren-Mora N, Raam MS, Kamat A, Chandrasekharappa SC and Solomon BD: Analysis of FOXF1 and the FOX gene cluster in patients with VACTERL association. Eur J Med Genet 54: 323-328, 2011.

60. Catala M: Genetic control of caudal development. Clin Genet 61: 89-96, 2002.

61. Grumolato L, Liu G, Mong P, Mudbhary R, Biswas R, Arroyave R, Vijayakumar S, Economides AN and Aaronson SA: Canonical and noncanonical Wnts use a common mechanism to activate completely unrelated coreceptors. Genes Dev 24: 2517-2530, 2010

62. Uysal-Onganer P and Kypta RM: Wnt11 in 2011 - the regulation and function of a non-canonical Wnt. Acta Physiol (Oxf) 204: 52-64, 2012. 